\title{
The first total synthesis and the second- or third- generation approach
}

The Journal of Antibiotics (2016) 69, 191; doi:10.1038/ja.2016.30

$I^{t}$ $\mathrm{t}$ is a great honor to publish the special issue entitled 'Amos B. Smith, III: 50 years of Research and Contributions - Featuring Outstanding Contributions to Complex Natural Product Total Synthesis, Bioorganic and Medicinal Chemistry' in The Journal of Antibiotics in 2016 under the supervision of Editor-in-Chief, Professor Kuniaki Tatsuta. Professor Amos B Smith, III graduated from Bucknell University (advisor: Professor Harold W Heine) in 1966 and started his academic career in the same year at the University of Pennsylvania.

In these 50 years, what he provided for mankind and human society is not only fantastic total syntheses of highly complex natural molecules, but many sophisticated academia, future-oriented scientific philosophy and exploration of extremely efficient process chemistry of biologically important molecules. Nowadays, the term 'efficient synthesis' often means short step synthesis exemplified by a story of total synthesis ${ }^{1-3}$ of hyperforin. The number of steps for total synthesis was greatly decreased from $>50$ to 18 (or 10 as racemic). On the other hand, Professor Smith has been investigating efficient and large-scale syntheses of, for example, highly complex drug candidates. Among them, continuous total synthetic studies ${ }^{4-7}$ of (+)-discodermolide are beyond expectation and provided the process chemists with many future aspects.

On 30 October 2002, Professor Smith visited our institute by kind consideration from Professor Sunazuka and introduced us brilliant progress of the second- and the third-generation total syntheses of $(+)$-discodermolide, as the most exciting topic in his laboratories. Because process chemistry was getting more popular those days even in Asian countries, it was really difficult for a chairman to stop arising questions after his lecture. Professor Smith has been more than great for a long time as long as I know.
For this special issue, his many outstanding postdocs, students and friends kindly submitted their fantastic manuscripts under the direction of Professor John L Wood. I would be more than happy only if the readers of our journal can feel big achievements that were derived from the world of Professor Smith. At the closing of this editorial, I would like to express sincere appreciation to Professor Amos B Smith, III for his continuous supervision and Ms Krista Leary for her valuable supports toward publication of this special issue.

\section{CONFLICT OF INTEREST}

The authors declare no conflict of interest.

Keiichi Ajito Department of Project Planning \& Management, Meiji Seika Pharma Co., Ltd., Tokyo, Japan E-mail: keiichi.ajito@meiji.com

1 Shimizu, Y., Shi, S.-L., Usuda, H., Kanai, M. \& Shibasaki, M. Catalytic asymmetric total synthesis of ent-hyperforin. Angew. Chem. Int. Ed. 49, 1103-1106 (2010).

2 Sparling, B. A., Moebius, D. C. \& Shair, M. D. Enantioselective total synthesis of hyperforin. J. Am. Chem. Soc. 135, 644-647 (2013).

3 Ting, C. P. \& Maimone, T. J. Total synthesis of hyperforin. J. Am. Chem. Soc. 137, 10516-10519 (2015).

4 Smith, A. B. III, Qiu, Y., Jones, D. R. \& Kobayashi, K. Total synthesis of (-)-discodermolide. J. Am. Chem. Soc. 117, 12011-12012 (1995).

5 Smith, A. B. III, Kaufman, M. D., Beauchamp, T. J., LaMarche, M. J. \& Arimoto, H. Gram-scale synthesis of (+)-discodermolide. Org. Lett. 1, 1823-1826 (1999).

6 Smith, A. B. III et al. Evolution of a gram-scale synthesis of (+)-discodermolide. J. Am. Chem. Soc. 122, 8654-8664 (2000).

7 Smith, A. B. III, Freeze, B. S., Brouard, I. \& Hirose, T. A practical Improvement, enhancing the large-scale synthesis of (+)-discodermolide: a third-generation approach. Org. Lett. 5, 4405-4408 (2003). 